\title{
LOOKING INTO THE CRYSTAL BALL -
}

\section{SWEDISH RADIOLOGY 2025}

\section{A QUALITATIVE STUDY OF POSSIBLE FUTURE}

\section{SCENARIOS}

Authors: Kent Fridell Inst. Department of Clinical Science, Intervention and Technology (CLINTEC) Karolinska Institutet E-mail: kent.fridell@,ki.se Jessica Ekberg, Department of Clinical Science, Intercention and Technology (CLINTEC) Karolinska Institutet E-mail: Jessica.ekberg@ki.se

PEER REVIEWED ARTICLE, VOL. 2, NR. 1, p. 15-29 PUBLISHED 30.11.2015

\section{Abstract}

Keywords: radiology, future research, scenario planning, future of radiology

\section{Introduction}

During the 20th century, the field of radiology experienced extraordinary growth and became an essential component of the practice of clinical medicine (Chan, 2002). In the 21st century, it is likely that radiology will continue to grow by interfacing with new and important domains such as information technology, molecular biology new tracers in nuclear medicine. This will require radiologists to understand the gaps between the new frontiers and the traditional core of radiology.

This article introduce the reader to one strategy management method, Scenario Planning, to identify, analyze and present four scenarios for the Swedish Radiology 2025. It also presents the trends that will affect the future of radiology

\section{Background}

If you don't know where you're going, any road will take you there, Alice in Wonderland Radiology of today

For many years radiology enjoyed a period of tremendous growth. This advancement was largely due to the advent of new technology, which greatly expanded the diagnostic capabilities of

Radiography Open 2015 Vol. 2

ISSN: 2387-3345 


\section{LOOKING INTO THE CRYSTAL BALL - SWEDISH RADIOLOGY 2025: A QUALITATIVE STUDY OF POSSIBLE FUTURE SCENARIOS}

imaging (Berlin and Lexa, 2012). Medical imaging had an enormous effect on the practice of medicine, so much that an imaging study is obtained at almost every medical encounter (Dunnick, 2015)

Fuchs and Sox (2001) describes in an article that doctors rate magnetic resonance tomography (MRI) and computer tomography (CT) as the two most important medical technologies of the last 30 years.

Radiology was also the first purely diagnostic speciality to expand its range into treatment as well, through interventional radiology (Goldsmith 2011). The potential for new treatments in the future in this field seems to be unlimited (Persson, 2010)

These technologies and procedures have continued to develop. In the article "Will Medical Visualisation tools meet medical user requirements in the future", Persson (2010) provides a very good description of this development. The first tomography scanner was installed in 1971, at which time it had a scanning time of five minutes, which is now down to 0.27 seconds with a layer thickness of 0.2 millimetres. These short scanning times mean that today it is possible to examine objects in motion, for example, the heart. The most recent development is the so-called multidetector CT, which has enabled production of actual 3-D reconstructions of examinations. We are also observing development of so-called multi energy CT, which enables production of two different energy levels during the examination, and a concomitant classification of different tissues, for example, cartilaginous tissue and ligaments.

The magnetic resonance imaging scanner (MRI) has developed similarly from when the first image was presented in 1973. From being able to display morphology, the technology has developed towards also displaying physiological processes (fMRI). Magnets, magnetic fields, new sequences and multi-channel coils are under development. This development is enabling even better tissue characterisation and all healthy tissue can be removed from the image in order to create "the pathological picture". Para magnetically marked pharmacological preparations, monoclonal antibodies, provide completely new possibilities to obtain information about physiological and pharmacological processes. The new "synthetic MRI" technology will provide new possibilities for tissue characterisation and will enable completely new methods which will deliver major opportunities for new modes of working.

We are also observing ongoing development in so-called hybrid machines, which combine Positron Emisssions, Tomography's physiological processes, with both MRI and computer tomography. A sensitive detection method with very good morphological information is obtained.

King et al write in Digitization of Medicine (2013) that the success of radiology has been due to walls having been built around radiologists so that they have been able to focus on interpreting, describing and reporting radiological images. This changed rapidly when the Picture Archiving and Communications System (PACS) was introduced within radiology. This enabled digital pictures to be available anywhere in the world almost as they were produced. For radiologists, 


\section{LOOKING INTO THE CRYSTAL BALL - SWEDISH RADIOLOGY 2025: A QUALITATIVE STUDY OF POSSIBLE FUTURE SCENARIOS}

this represented the potential for a major change and meant that they went from having been "Individual professional experts" to "Actors in networks", where forms of cooperation with clinical colleagues increasingly expanded (Fridell, 2011)

Chan provides a general description of today's radiology as:
a) An information technology
b) An important teaching method for medical education
c) An independent research discipline
d) Diagnostic technology with a direct effect on patient outcome
e) An important instrument for screening and early detection of illness
f) A visualisation technology which contributes to "minimal invasive therapy"

\section{(Chan,2002)}

Successful groups within radiology can exploit this position through offering both quantitative and qualitative analyses of patient data and through displaying the added value created within radiology. Evaluating, measuring and demonstrating these added values will be a challenge and opportunity for radiology in the future (Sharpe, Mehta, Eisenberg \& Kruskal, 2015)

At the same time as radiology continues to grow and develop, there is an increased interest in preparing it for the future (Ernest, 2000).

\section{Methodology}

\section{Scenario planning - An overview of Strategic planning}

Health and medical care has long had prerequisites that are different from other activities in society as it has been funded through taxation

Visions, goals, strategies and critical success factors are terms introduced since the nineteen eighties (Kaplan \& Norton, 1996). They paved the way for "strategy management methods" or administrative methods based on methods for strategic planning". In recent decades, extensive reforms have been implemented within the public sector both in Sweden and in many other countries. Increased demands for effectiveness have been an important reason for this. The changes have primarily been implemented through the introduction of forms of management derived from the private sector, so-called market-oriented forms, e.g. through privatisation and opening up to competition.

Methods for strategic planning have long been present in organisations within the business world, the military and in economics (Cook, Wintle, Aldrich \& Wintle, 2014). A very early book in the field was written in China as far back as 2,000 years ago (Tzu, 1994), which addresses how war should be conducted on the basis of strategic perspectives. 


\section{K.Fridell, J. Ekberg \\ LOOKING INTO THE CRYSTAL BALL - SWEDISH RADIOLOGY 2025: A QUALITATIVE STUDY OF POSSIBLE FUTURE SCENARIOS}

These strategic methods can be divided into three categories:

1. Forecasts - a projection of a historically observed trend

2. Scenarios - which describe different potential pictures of the future or a desired future (Scenario Planning, Backcasting and Forecasting).

3. Expert advice - the most common method is called Delfi and uses a panel of experts (Framtider no. 1 (2000), Institute for Future Studies, Framtider no. 2 (2002), Institute for Future Studies)

\section{Scenario Planning - description of the method}

\section{"If you do not change direction, you may end up where you are heading" Lao Tse}

Thinking in terms of scenarios is a mechanism of using clues to prepare ourselves for the future. It is based on our ability to envisage the future in relevant and feasible narratives. Through utilising our previous experience and knowledge, we create images of the future using our capacity to tell stories and consider consequences logically.

The method of doing this for operational planning is usually called scenario planning and has its origin in the military's strategic analyses. During the increasing turbulence within the oil and energy sectors in the 1970s and 1980s, Royal Dutch/Shell further developed the method to enable navigation in an increasingly uncertain and changeable world. Today the method is more relevant than ever. It is no longer used solely by large companies with long-term time perspectives, but today is a key tool in strategic planning for just about all types of organisations.

There is no simple definition of Scenario Planning. Based on the literature, Lindgren \& Bandhold (2008) describes four different definitions of the method. However, what is clear is that it is not the same as a "forecast", i.e. a projection of the present that does not contain any major surprises. Neither is it a "vision", which can most closely be described as a desired future. Both of these can have a tendency to conceal the risks. In the scenario form we are able to identify and manage risks (a.a).

Scenario planning is not about predetermining a single possible future, because it is likely that there are a number of possible futures. The aim is rather to use scenario planning to describe several different possible futures and, in the final analysis, to understand which of them is the most likely (Lexa \& Chan, 2010) and (Enzmann, Beauchamp \& Norbash, 2011)

Ghanem (2015) writes that scenarios found are not meant to predetermine the future. Instead, they are meant to inspire ideas to prepare for future challenges and then to develop strategies and "action plans" to remain competitive in a dynamic and changeable context.

Despite the method having a long history and being used within several areas, it has not been utilised within health and medical care to such an extent as other "future methods" e.g. the "Delphi technique". In 'Using the scenario method in the context of health care - a scoping review",

Radiography Open 2015 Vol. 2

ISSN: 2387-3345 


\section{LOOKING INTO THE CRYSTAL BALL - SWEDISH RADIOLOGY 2025: A QUALITATIVE STUDY OF POSSIBLE FUTURE SCENARIOS}

Vollmar, Ostermann \& Redaèlli (2015) review published material where precisely Scenario Planning has been the method used for the study. The results revealed 41 articles with 38 scenarios, with the vast majority published after 2000 and covering a wide variety of areas. The majority studied various illnesses with a major focus on dementia and cancer. Next was the public health issue, often described in terms of organisational forms. There were also studies which described future labour markets for health and medical care staff. One study focuses on the radiological field (Enzmann, 2011). It describes three possible scenarios for the future of American radiology.

As the Scenario planning method has been used over a long period and developed within the military, and in order to simultaneously obtain an overview of the process, the method's application is described on the basis of this activity:

1. Decide on the key question to be answered by the analysis

2. Set the time and scope of the analysis

3. Identify major stakeholders

4. Map basic trends and driving forces

5. Find key uncertainties. Map the driving forces on two axes, assessing each force on an uncertain (relatively) predictable and important/unimportant scale.

6. Check for the possibility to group the linked forces and if possible, reduce the forces to the two most important. (To allow the scenarios to be presented in a neat xydiagram

7. Identify the extremes of the possible outcomes of the two driving forces and check the dimensions for consistency and plausibility.

8. Define the scenarios, plotting them on a grid if possible. Usually, two to four scenarios are constructed.

9. Write out the scenarios. Narrate what has happened and what the reasons can be for the proposed situation.

10. Assess the scenarios. Are they relevant for the goal? Are they internally consistent? Are they archetypical?

11. Identify research needs

12. Develop quantitative methods. If possible, develop models to help quantify consequences of the various scenarios, such as growth rate, cash flow etc.

13. Converge towards decision scenarios. Retrace the steps above in an iterative process until you reach scenarios which address the fundamental issues facing the organization.

(Scenario Planning, 2015)

\section{Aim}

The study aims to identify, analyze and present four scenarios for the Swedish Radiology 2025.

\section{Method and analysis}

\section{Data collection}




\section{K.Fridell, J. Ekberg \\ LOOKING INTO THE CRYSTAL BALL - SWEDISH RADIOLOGY 2025: A QUALITATIVE STUDY OF POSSIBLE \\ FUTURE SCENARIOS}

\section{"If you want to know how people apprehend their world and their lives, why not ask them"(Kvale \& Brinkman, 2009, s.15).}

Further, Kvale \& Brinkman consider that the qualitative research interview provides knowledge about the surveyed person's own experiences, feelings, opinions and viewpoints. Olsson\& Sörenssen (2011) consider that research interviews are a subject-oriented conversation between individuals, with one of them talking about a subject in which both are interested, with the aim of obtaining nuanced descriptions of different qualitative aspects of the interviewee's world. Personal aspects of the interviewee can be addressed which are usually taken as given, perceived experiences and values for example (Ahrne \& Svensson, 2011). The conversational form provides the opportunity to use very open questions during the course of the conversation, enabling the respondent to describe what feels most important in terms of the relevant theme (Patel \& Davidson, 2008). The benefits of individual interviews are that they produce detailed and complete answers and that the opportunity exists to immediately clear up misunderstandings, as well as provide the opportunity for supplementary questions in order to advance the lines of thought the respondent has started. The individual interview thus provides a more wide-ranging picture with nuances and dimensions (Ahrne \& Svensson, 2011; Ejvegård, 2003).

A qualitative perspective with an "open interview" was used for the study. The interview followed the process inspired from Scenario Planning methodology, where trends are identified which have influenced the present situation, but will also affect the future. What then is meant by a trend? "A trend is something which constitutes a more profound change and not just a temporary fashion. If we make a comparison with meteorology, trends would be climate changes rather than variations in the weather (Lindgren \& Bandhold, 2008 p. 70):

The interview guide that was used equally in all interviews is described below; this guide follows the steps for the Scenario Planning methodology:

- Describe trends which have influenced radiology's current status

- Of these, describe the trends which will continue to shape the future of radiology

- Do you perceive any "new" trends which will influence the future of radiology

- Summary of trends described

- Evaluation of the trends based on the trend's future development and the significance it has for the development of the issue

- Select the two trends which you regard as the most "uncertain", but which if they were to come about would have a major impact on radiology in the future

- Scenario cross - which scenario do you feel is the most likely

\section{Sample}

In qualitative studies, a representative sample is not what is of interest, rather it is about finding those individuals who have something to recount, this mode of procedure is designated strategic sample (Morgan \& Kreuger, 1998). The participants are selected in accordance with the project's goal and the aim of the study.

In the strategic sample for the in-depth interviews, it was important that the specific aim could be reflected from different perspectives. A strategic sample with the emphasis on variation can provide more material to develop new hypotheses and challenge deductions that might initially 


\section{LOOKING INTO THE CRYSTAL BALL - SWEDISH RADIOLOGY 2025: A QUALITATIVE STUDY OF POSSIBLE FUTURE SCENARIOS}

seem obvious. A range of variation also provides the opportunity to describe a number of nuances of the same phenomenon (Malterud, 2009). A method of selection called "key informant technique" was used for the study. This entails selecting informants who are viewed as "experts" within the subject, and who are simultaneously the most suitable for the study (Marshall, 1996 in order to find different conceptions surrounding the study's aim "how do radiologists describes Radiology in 2025", and use these descriptions to enable an illustration of this future by means of the Scenario Planning methodology which has a so-called "scenario cross" as the final result. The persons selected for the study were discussed with a radiologist with long and wide-ranging experience of radiology. The sample consisted of five professors with different specialities as their background, but also with experience as head of a clinical department. There was a large geographic distribution as it extended from north to south Sweden.

\section{Results}

\section{The scenario cross}

The outcome of a Scenario Planning process is presentation of the two trends which are most uncertain, but which have the most impact on the issue if they come about. These are put together in an $\mathrm{x}$ and $\mathrm{y}$ diagram, which then gives the four conceivable scenarios or futures. They are given an overall name and a more detailed explanation of the content that might be found in the potential future scenario presented is subsequently provided.

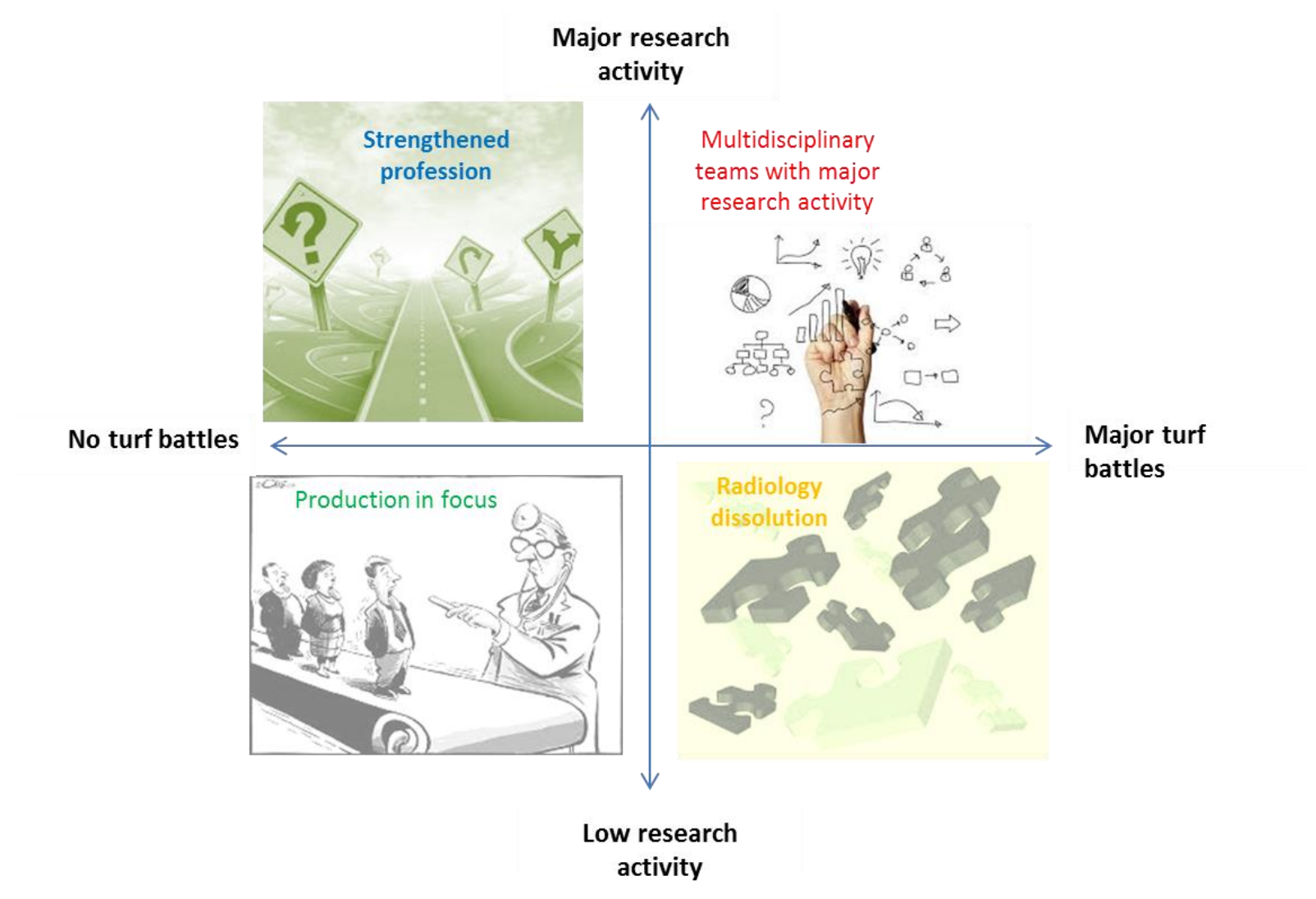

The outcome of a Scenario Planning study is "certain trends" and "uncertain trends". "Certain trends" are factors which are very likely to influence the future, while "uncertain trends" are 
factors regarding which there is less certainty. However, if they are included, they will have the greatest impact in the future. These "uncertain trends" are put together and constitute a fourfold diagram with four alternative future scenarios.

\section{Certain trends}

\section{Turf battles}

Under this category the interviewees discussed a process that has been proceeding over a long period. It was called 'turf battles" in the study as this was an expression used by the interviewees. Turf battles in this study means that there are a large number of tasks within radiology which are also related to clinical specialities. A clear example is percutaneous coronary intervention (PCI), where the necessary equipment is usually available in a radiological department as it uses X-rays for fluoroscopy. The examination and subsequent treatment was initiated by radiologists, however, over the years it has been gradually transferred, so that it is now performed by cardiologists. In other words, for various reasons, a clear 'turf battle"' has taken place in this context over the years between radiologits and cardiologists.

\section{Changed the outcome of the diagnostics}

A lot was discussed regarding the new management forms which are emerging, the most recent labelled "value based healthcare", and the clear indication was that in the future radiology will increasingly have to display the added value which the speciality provides, as well as the clinical benefits of radiological examinations.

\section{New technologies}

In relation to this trend, the interviewees discussed the fact that the technological development will not change, rather the view is that there will be a similar development in the future as has been observed within radiology during the last 40 years, with new technologies being launched at regular intervals. It was felt that this was the effect of this development usually being performed by large multinational medical technology companies. Their driving force and continued survival is precisely new technologies. Computer Aided Diagnosis (CAD) was mentioned as a possible future tool which could also be valuable for the future development of radiologists and that it held great potential.

\section{Research activity}

This trend was highly absorbing and produced a lot of lively discussion when it was presented by the informants. The suggestion was that this was important for Swedish radiology and also for its prominent role internationally. Numerous well known examples of Swedish research and innovation were reported with perhaps the most prominent being the so-called 'Seldinger technique', which revolutionised angiographic technology and examination method. The Radiography Open 2015 Vol. 2

ISSN: 2387-3345 
professors interviewed felt that Sweden had been among the leaders within radiological research, but that for several years it had increasingly been taking a back seat. The professors meant that the reason for this retrogression was that radiology in Sweden redirected its focus from research to production due to the fact that policy measures were introduced which provide less room for research and knowledge development.

\section{Organizational structure}

This trend related to the discussion the professors interviewed had concerning organisation of the radiology department. The feeling was that there were two clear, principal differences in how this organisation can be configured. In the first case, the radiology department is unified around different parts or sections. This division is based on the clinical specialities and entails the referring clinics visiting, on a daily basis, the radiology department in connection with presentation and discussion of the preceding examinations. It also means that the modalities present in the unified department such as DT, MRI and ultrasound are utilised by all referring clinics.

In distinction to this, another organisational structure was reported that instead focussed on the clinical specialities. This means that for clinical specialities such as Neuro or Thorax there is also an integrated radiological operation in the vicinity.

Discussions regarding this trend presented both positive possibilities and negative aspects.

A positive element of being unified is that it can provide benefits in terms of resources as all equipment is assembled, while in terms of being divided, the proximity to the clinical speciality could then simultaneously provide a broader base for recruitment of doctors interested in radiology.

\section{New specialties: General radiology and Emergency radiology}

The possibility or need for new specialities in the future within radiology also emerged in several interviews. These included a general radiological speciality and in part emergency radiology. This discussion related to future recruitment and development of radiology. There is a high level of awareness that it must also be possible to offer radiological examinations to people outside the large cities

In this context, a discussion also emerged concerning the planned hybrid wards which are being increasingly introduced, where a radiological intervention can become an open surgical operation.

\section{The most uncertain of the trends described above}

The Scenario Planning process identified the two trends which were regarded as having the greatest impact on radiology in the future. These two trends were judged to be the most 


\section{K.Fridell, J. Ekberg \\ LOOKING INTO THE CRYSTAL BALL - SWEDISH RADIOLOGY 2025: A QUALITATIVE STUDY OF POSSIBLE \\ FUTURE SCENARIOS}

uncertain of the trends identified. Turf battles and Research Activity were appraised as the two trends which the interviewees regarded as most uncertain, but with the greatest impact on radiology in the future.

\section{Discussion}

The scenario cross consists of the two trends "research activity" and "turf battles". When these are put together in an xy-diagram, four scenarios emerge, representing four possible futures, depending on how the two axes are affected.

The scenario where we observe "no turf battles", in other words, the radiologists retain all their job assignments and there is no research activity. In this scenario, we interpret the X-ray department as a "Production in focus". There is thus a major focus on producing a large number of examinations.

In another scenario, we do not observe 'any job slippage", but a high level of research activity. We interpret this as a return to Swedish radiology when it was at the peak of its development. We call the scenario "Strengthened profession" This potential future is discussed by (Goldsmith, 2011). There may be a risk of the profession putting a lot of energy into "turf battles" with other disciplines/specialities, and it missing opportunities to develop the major potential that is built into the modalities that radiology utilises. In order to create the requisite added value that clinics and patients expect from radiology, it is of the utmost importance to develop clinical opportunities or, as the author concludes, "the best defence is a good offence"

In a third scenario we observe "major job slippage", but "no research activity". We call this scenario "Radiology dissolution". Our interpretation of this scenario is that job assignments are performed by a larger number of specialities, but there is no knowledge development in the radiology department. This might mean that the different specialities absorb the existing tasks into their own clinics. This scenario can show that it is widely felt that radiology will be increasingly important and that this will produce knowledge that is important for the future and for that reason, the different disciplines realise the significance of internalising the various diagnostic options (Krestin, 2009). The author provides examples of cardiologists who purchase in their own CT and paediatricians who procure MR for emergency treatment.

In the fourth scenario, we observe "major turf battles", but also "a high level of research activity". This means that there are lots of specialities in the radiology department and a high level of activity in research and knowledge development. Given the name "Multidisciplinary team with major research activity". Can mean that different specialities work together and participate in joint research projects on equal terms. (Margulis (2011) describes this scenario very well. The argument for this is that it is not just radiology that needs to become more multidisciplinary, but rather medical and health care as a whole, as both science and technology are developing rapidly and the modalities we are observing today are being increasingly integrated in each other, and we are observing new biomarkers and trace elements in the market. This future 


\section{K.Fridell, J. Ekberg \\ LOOKING INTO THE CRYSTAL BALL - SWEDISH RADIOLOGY 2025: A QUALITATIVE STUDY OF POSSIBLE FUTURE SCENARIOS}

demands knowledge from several different specialities to be fully exploited. Krestin (2009) notes that the radiologists of the future will have to be very open to change and above all to collaborations with clinical colleagues in order to create the necessary added value that is expected. Goldsmith (2011) observes in "The future of radiology in the new healthcare paradigm" that a similar scenario provides opportunities to build "centres of excellence".

The results of the analysis display six trends which in different ways can affect Swedish radiology, two of which were formulated as those which were most "uncertain", but if they do come about, will have the "greatest impact". The "uncertain" was "turf battles" and "research activity".

The trend "turf battles" is a factor all interviewed radiologist professors mentioned that may affect the future. The description of " turf battles " describes more a process of defending what you have, but what they describe is more a slow process where the work is transferred from one profession to another, when the context change. There are several examples of this when "duties" are transferred to another profession (Fridell, 2011)

An early examples of this "turf battles" is coronar angiography. Coronary angiography was developed by radiology physicians Judkins and Amplatz in the sixties, and was performed by radiologists through the seventies, but almost none is performed by radiologists today (Judkins, 1967).

Control of patients is not the purview of radiologists. In addition, most radiologists lack clinical training and expertise in the medical subspecialties encroaching on their turf. A clear disconnect often exists between the radiologist and the patient, and the radiology report is at best a surrogate for interaction with clinical colleagues. These factors undermine the radiologist's position in deliberations over turf management

Today, turf battles exist throughout the scope of radiology's practice, in ultrasound; skeletal and chest radiography; bone densitometry and cardiac nuclear studies; urinary, musculoskeletal, and vascular interventions; and neurointerventions (Bello, 2012)

When "research activities" was discussed, this trend attracted great interest and gave very lively discussion. Sweden has been among the leaders in radiological research, but its position has been declining for several years now. The reason for this was that radiology in Sweden have switched focus from research to production.

Promoting high-quality imaging research is essential for radiology to maintain a presence and relevance in today's practice of medicine. An effective strategy for this is through groundbreaking, high-level research. Emphasis must be placed on multicenter clinical trials to define best practices in radiology and evaluate clinical outcomes for radiologist practices compared with those of nonradiologist physicians (Bello, 2012).

Under the heading "new technology", all the interviewees were in complete agreement that new technological innovations will emerge, including those that we cannot imagine today. Modern radiology is always at the forefront of technological progress in medicine, a position that often places unique challenges on its professional character (Hryhorczuk, \&Hanneman, Eisenberg, Radiography Open 2015 Vol. 2

ISSN: 2387-3345 


\section{LOOKING INTO THE CRYSTAL BALL - SWEDISH RADIOLOGY 2025: A QUALITATIVE STUDY OF POSSIBLE FUTURE SCENARIOS}

Meyer \& Brown, 2015).

Information technology has brought stunning changes to radiology. Informatics innovations of the past 30 years have improved radiology quality and efficiency immensely. Radiologists are groundbreaking leaders in clinical information technology (IT)

The technological revolution enabling PACS has also created platforms for teleradiology. Because radiologists no longer require proximity to clinical colleagues or patients, teleradiology makes care possible in remote locations where radiologists may not be physically present (Kohli, Dreyer and Geis, 2015)

On the other hand, what was discussed was that we are perhaps not utilising the potential that there already is in the existing technology between the different modalities we can observe in a modern radiology department. In 'Radiomics: Images Are More than Pictures, They Are Data", Gillies, Kinahan and Hricak (2015) discuss that in contrast to the traditional practice of treating medical images as pictures intended solely for visual interpretation have, in the past decade, the field of medical image analysis has grown exponentially, with an increased number of pattern recognition tools, tools to develop models that may potentially improve diagnostic, prognostic, and predictive accuracy.

\section{Conclusion}

The future of Radiology represent unprecedented opportunities and challenges for radiologists. This study used a well-known method, in other business, called Scenario Planning to describe possible futures of radiology.

In conclussion four future scenarious were identified for Swedish radiology 1) Production in focus

2) Strengthened profession 3) Radiology dissolution 4) Multidisciplinary teams with major research activity The realization of these scenarios is dependent on the evolution of many different factors. Thus is the realization of each and every scenario linked with a high extent of uncertainty. In all, the glass-ball do not tell what will happen it only identifies what can happen. However, if you know what can happen you also have the possibility to steer your actions so factors increase the probability of a certain scenarios realization. In this presented scenario cross to trend of factors were represented, research activity and turf battles. As an individual it is hard two affect these trends or factors but as a community it is possible.

This was the first Scenario Planning study done on Swedish Radiology and have its limitation but describes both trends and far-term opportunities. Much more research is needed to map out a complete overview. But the study shows an opportunity for radiologists to form new alliances and relationships with other disciplines and specialties, and to lead the way in ushering in a era of patient-centered, collaborative, and team-based care. 


\section{References}

Ahrne, G.\& Svensson, P. (2011). Handbok i kvalitativa metoder. (1. ed.) Malmö: Liber.

Bello, J. (2012). Turf issues in radiology and its subspecialties. Neuroimaging Clinics of North America, 22(3):411-419. doi: 10.1016/j.nic.2012.04.006.

https://doi.org/10.1016/j.nic.2012.04.006

Berlin, J.W \& Lexa, F.J. (2012). Strategic Planning for Neuroradiologists. Neuroimaging Clinics of North America, 22(3): 403-409. doi: 10.1016/j.nic.2012.04.007

https://doi.org/10.1016/j.nic.2012.04.007

Chan, S. (2002) The importance of strategy for the evolving field of radiology. Radiology, 224(3), 63948. doi:

https://doi.org/10.1148/radiol.2243011390

Cook, C.N., Wintle, B.C., Aldrich, S.C. \& Wintle, B.A. (2014). Using strategic foresight to assess conservation Oppurtunity. Conservation Biology, 28:6, 1474-1483. doi: 10.1111/cobi.12404. Epub 2014 Nov 7.

https://doi.org/10.1111/cobi.12404

Dunnick, N.R. (2015). Reflect on the Past, Plan for the Future. Radiology, 276(2), 318-21. doi: 10.1148/radiol.2015150307

https://doi.org/10.1148/radiol.2015150307

Ejvegård, R. (2003). Vetenskaplig metod. (3., ed.) Lund: Studentlitteratur.

Enzmann, D.R., Beauchamp, N.J. \& Norbash, A. (2011). Scenario Planning. Journal of the American College of radiology, 8(3):175-9. doi: 10.1016/j.jacr.2010.08.022

https://doi.org/10.1016/i.jacr.2010.08.022

Ernest, J.F (2000). Consensus Conference Seeks New Pathways for Radiology Education. Radiology, 219(3), 589-590. DOI: http://dx.doi.org/10.1148/radiology.219.3.r01jn26589

https://doi.org/10.1148/radiology.219.3.r01jn26589

Fridell, K. (2011). A walk into the digital world - A long and winding road. Doctor thesis, Karolinska Institutet, Division of Medical Imaging and Technology Department of Clinical Science, Intervention and Technology.

http://publications.ki.se/xmlui/handle/10616/41212

Fuchs, V.R., Sox, H.C. (2001). Physicians' views of the relative importance of thirty medical innovations. Health Affairs (Millwood) 20(5):30-42

https://doi.org/10.1377/hlthaff.20.5.30

Ghanem, M., Schnoor, J., Heyde, C.E., Kuwatsch, S., Bohn, M. \& Josten, C. (2015); Management strategies in hospitals: scenario planning. GMS Interdisciplinary Plastic and Reconstructive Surgery DGPW, 22:(4):Doc06.

doi: 10.3205/iprs000065. eCollection 
Gillies, R.J, Kinahan, P.E, Hricak, H. (2015) Radiomics: Images Are More than Pictures, They Are Data. Radiology,18-151169. http://dx.doi.org/10.1148/radiol.2015151169

https://doi.org/10.1148/radiol.2015151169

Goldsmith, J. (2011). The future of Radiology in the New Health Care Paradigm; the Moreton Leture. Journal of the American College of radiology,;8(3):159-63. doi: 10.1016/j.jacr.2010.08.024 https://doi.org/10.1016/i.jacr.2010.08.024

Hryhorczuk, A.L, Hanneman, K, Eisenberg, R.L, Meyer, E.C and Brown, S.D. (2015) Radiologic Professionalism in Modern Health Care. Radiographics: 35(6):1779-88. doi: 10.1148/rg.2015150041 https://doi.org/10.1148/rg.2015150041

Judkins, M.P. (1967). Selective coronary arteriography. I. A percutaneous transfemoral technic. Radiology 89: 815-824.

https://doi.org/10.1148/89.5.815

Institutet för framtidsstudier. (2000). Framtider: Demografi \& demokrati nr 1 Tillgänglig:

http://www.iffs.se/publikation/artiklar-i-framtider-nr-12000-2/ (2015-11-16)

Institutet för framtidsstudier. (2002). Framtider: Stad och land nr 2 Tillgänglig:

http://www.iffs.se/publikation/artiklar-i-framtider-nr-22002/ (2015-11-16)

King, C.L, Marcovici, P, Phelps, A, Potter, C, Tillack, A, Tomich, J \& Tridandapani, S. (2013). Digitization of Medicine - How Radiology Can Take Advantage of the Digital Revolution. Academic radiology, 20:12, 1479-1494

https://doi.org/10.1016/j.acra.2013.09.008

Kohli, M, Dreyer, K.J \& Geis, J.R. (2015). Rethinking radiology informatics. American Journal of roentgenology, 204(4):716-20. doi: 10.2214/AJR.14.13840.

https://doi.org/10.2214/AJR.14.13840

Krestin, G.P. (2009). Maintaining Identity in a Changing Environment: The Professional and Organizational Future of Radiology. Radiology,250(3):612-7. doi: 10.1148/radiol.2503081791. https://doi.org/10.1148/radiol.2503081791

Kvale, S. \& Brinkmann, S. (2009). Den kvalitativa forskningsintervjun (2. Ed). Lund: Studentlitteratur $\mathrm{AB}$.

Lexa, F.J., Chan, S. (2010). Scenario analysis and strategic planning: practical applications for radiology practices. Journal of the American College of radiology, 7(5):369-73. doi:

10.1016/j.jacr.2009.12.012.

https://doi.org/10.1016/j.jacr.2009.12.012

Lindgren, M \& Bandhold, H. (2008). Scenarioplanering: Länken mellan framtid och strategi. Uppsala: Uppsala Publishing House.

Malterud, K. (2009). Kvalitativa metoder i medicinsk forskning. Lund: Studentlitteratur AB. 
Margulis, A.R. (2011) The future of radiology. Rambam Maimonides Medical Journal, 2(3): e0059. doi: 10.5041/RMMJ.10059

https://doi.org/10.5041/RMMJ.10059

Morgan, D.L. \& Krueger, R.A. (1998). Planning focus groups. Focus group kit. Vol. 2. California: SAGE Publications, Inc.

https://doi.org/10.4135/9781483328171

Marshall, M. (1996) The key informant technique. Oxford University Press. Olsson, H. \& Sörensen, S. (2011). Forskningsprocessen: kvalitativa och kvantitativa perspektiv. (3. ed.) Stockholm: Liber https://doi.org/10.1093/fampra/13.1.92

Patel, R. \& Davidson, B. (2008). Forskningsmetodikens grunder - Att planera, genomföra och rapportera en undersökning. (4 ed). Lund: Studentlitteratur

Persson, A. (2010) Will medical visualisation tools meet medical user requirements in the future? Radiation Protection Dosimetry, 139(1-3):12-9. doi: 10.1093/rpd/ncq018. Epub 2010 Feb 16. https://doi.org/10.1093/rpd/ncq018

Scenario planning (2015). I Wikipedia. Retrieved Nov 16, 2015, from https://en.wikipedia.org/wiki/Scenario planning\#cite noteScenarios: An Explorer.27s Guide-25

Sharpe, R.E., Mehta, T.S, Eisenberg, R.L. \& Kruskal, J.B. (2015). Strategic planning and radiology practice management in the new health care environment. Radiographics, 35(1):239-53. doi: 10.1148/rg.351140064.

https://doi.org/10.1148/rg.351140064

Tzu, S. (1944), The art of War. New York: Dover Publications Inc.

Vollmar, C.H., Ostermann, T. \& Redaèlli, M. (2015) Using the scenario method in the context of health care - a scoping review. BMC Medical Research Methodology, 16, 15:89 doi:10.1186/s12874015-0083-1

https://doi.org/10.1186/s12874-015-0083-1 